\title{
F-Fluorocholine PET/CT in the Assessment of Primary Hyperparathyroidism Chehab Nasreddine ${ }^{1^{*}}$
}

${ }^{1}$ Department of Nephrology Cheikh Khalifa International University Hospital, Mohammed VI University of Health Sciences (UM6SS), Casablanca, Morocco

*Corresponding author: Chehab Nasreddine

Abstract

Confirmation and localization of parathyroid adenomas remain difficult in imaging to date. Often, several imaging tests are necessary for the location of the adenoma (echography, scintigraphy). Recently, limited series have shown a potential benefit of PET to fluorocholine. Here we report the case of a patient initially operated for primary hyperparathyroidism with persistence of a high PTH in post-operative suites and whose MIBI scintigraphy did not detect a persistent parathyroid nodule.

Keywords: echography, scintigraphy, MIBI scintigraphy, Hyperparathyroidism.

Copyright $\odot 2021$ The Author(s): This is an open-access article distributed under the terms of the Creative Commons Attribution 4.0 International License (CC BY-NC 4.0) which permits unrestricted use, distribution, and reproduction in any medium for non-commercial use provided the original author and source are credited.

\section{INTRODUCTION}

Hyperparathyroidism is a common endocrinologist disorder defined by an abnormally high concentration of parathyroid or parathormone hormone in the blood. Primary hyperparathyroidism affects 1 in 10,000 patients and is significantly more common in women over 50 with a prevalence of 1,500 in this population.

The first-line treatment of the HPTP is surgical but the success of the surgery requires beforehand to have located precisely the causal lesion thanks to a presurgical imaging test. This assessment classically includes a cervical ultrasound and a scintigraphy of parathyroid and the surgery is performed preferentially when the two imageries are positive and consistent.

In recent years, the Positron Emission Tomography at $18 \mathrm{~F}$-Fluorocholine has taken an increasing place in this assessment, particularly in cases where ultrasound and scintigraphy are negative and / or discordant or after failure of surgery.

\section{Patient and Observation}

It was a 60-year-old patient followed for high blood pressure since 30, hypothyroidism under hormone replacement therapy, operated for right-lower isthmo-lobar parathyroid hyperplasia diagnosed on MIBI scintigraphy. She was admitted for pain left chest lasting 15 days. The clinical examination objected to an increase in heart noise with dry mouth and conjunctival syndrome. The biological balance found normal renal function without hydro-electrolytic disorder with discovery of persistent hyperparathyroidism at $168 \mu \mathrm{g} /$ 1. cardiac evaluation reveals pericarditis of autoimmune origin. As part of a systemic lupus treated with colchicine and nonsteroidal anti-inflammatory drugs.

The immunological balance: in search of a systemic lupus erythematosus objectified negative antinuclear antibodies and anti-DNA AC, soluble anti-SSA and Anti-SSB very positive, anti-Sm, Anti-Scl70, AntiJo1, Anti CENP-B, Ribosome $\mathrm{P}$ Proteins had all returned negative. After consultation with the internists, corticosteroid therapy at full dose was initiated orally.

TEP-TDM fluorine-labeled choline: basicervical hyper metabolic nodules suggestive of bilateral parathyroid adenomas.

\section{DiscUSSION}

Confirmation and location of parathyroid adenomas remain difficult to imagery to date. Often, several imaging tests are necessary for the location of the adenoma (echography, scintigraphy). Recently, limited series have shown a potential benefit of PET in fluor choline [2].

The limits of scintigraphy are its reduced susceptibility in case of moderate biological hypercalcemia and / or hyperparathyroidism values [3], in case of small parathyroid or multi-glandular pathology [4], which is the case for our patient. 
It is recommended that cinacalcet be stopped two weeks before performing sesta-mibi scintigraphy due to its inhibitory effect on parathyroid crown activity decreasing the sensitivity of the exam $[5,6]$.

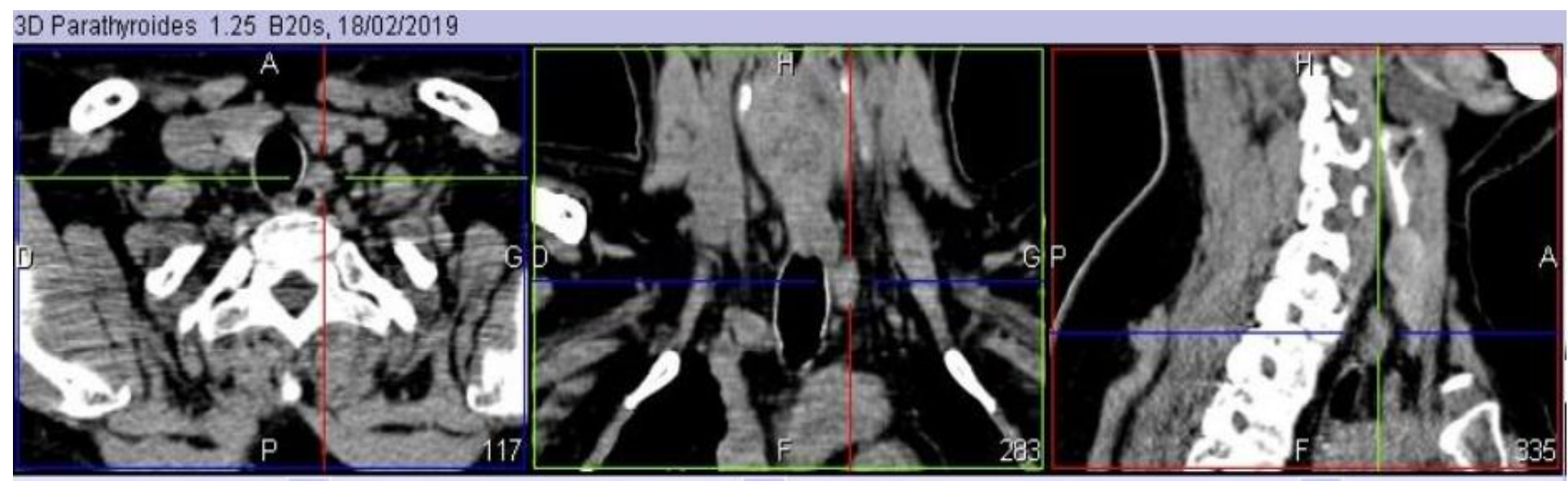

TOMO Tc99m [Recon SC- $\overline{A C}], 18 / 02 / 2019$

3D Parathyroides 1.25 B20s, $18 / 02 / 2019$

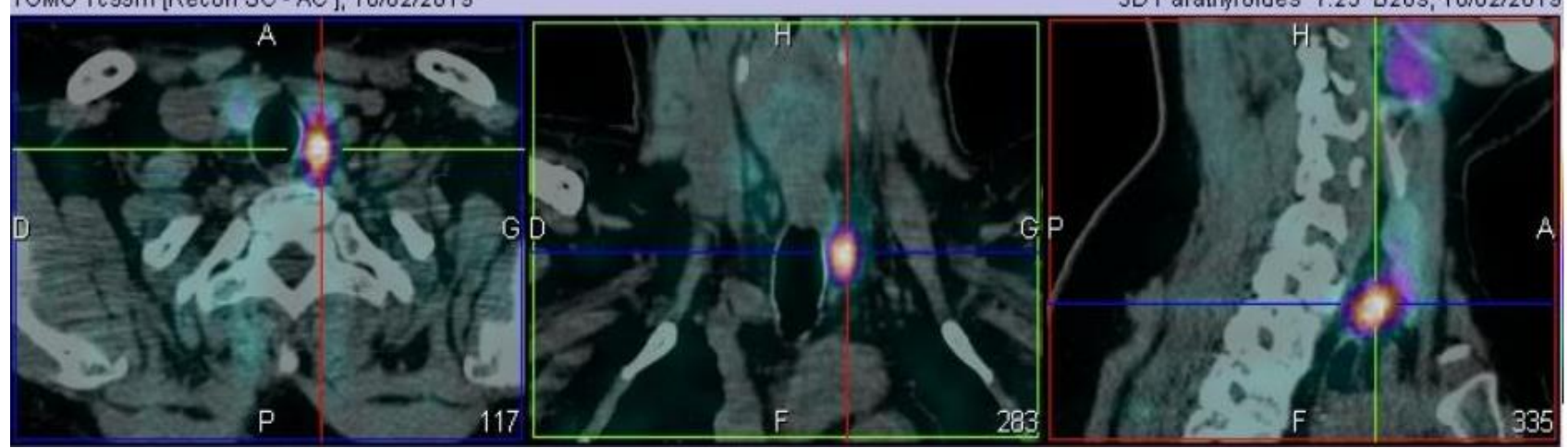

Fig-1: Multi-planar images TDM (top) and sestamibi tomoscintigraphy coupled to CT (bottom) centered on the cervicomediastinal region showing a strongly hyperfixing rounded tissue formation behind the left thyroid lobe corresponding to a left infamous parathyroid adenoma [1]

The main differential diagnosis of HPT is familial hypocalciuric hypercalcemia which is a genetic disease combining moderate hypercalcemia, more or less marked hypocalciuria, normal phosphoremia and normal or high PTH 1-84. The sequencing of the CSR gene confirms the diagnosis of type 1 hypocalciuric familial hypercalcemia ( $65 \%$ of cases).

Other differential diagnoses may be discussed depending on the case in the face of hypercalcemia, but they are generally associated with low PTH.

- Paraneoplastic hypercalcemia involves a protein derived from PTH and which has the same biological effects, parathormone related protein or PTHrp. This protein is found naturally in small quantities in the body but can be massively secreted by the cells of certain types of cancers (breast, lung, ENT and kidney cancers) or lymphomas.

- Multiple myeloma and plasmacytoma by excessive secretion of interleukin 6 which activates osteoclasts, which cause release to the blood of bone calcium.

- Osteolytic metastases of solid cancers or hemopathies, the bone lesions of which cause calcium to release into the blood.
- Sarcoidosis, whose granulomatous cells can secrete 1 alpha-hydroxylase which causes extra-renal hyperproduction of vitamin D with hypercalcemic effects.

\section{CONCLUSION}

TEP at $18 \mathrm{~F}-$ Choline, pre-operatively in the exploration of primary hyperparathyroidism, is characterized by a high positive sensitivity and predictive value in line with the performances described in the literature. It can be considered as an expensive but very effective imaging technique for the identification of pathological parathyroid glands.

\section{RÉFÉRENCE}

1. Shields T. La TEP-TDM à la fluorocholine dans le bilan d'hyperparathyroïdie primaire: expérience amiénoise. 2019.

2. Dubreuil J, Morelec I, Skanjeti A, Got P, Tordo J, Lapras V, Denier ML, Giammarile F, Lifante JC. Intérêt de la TEP-choline dans le bilan d'hyperparathyroïdie: résultats préliminaires. Médecine Nucléaire. 2016 May 1;40(3):180.

3. Parikshak M, Castillo ED, Conrad MF, Talpos GB. Impact of hypercalcemia and parathyroid hormone level on the sensitivity of preoperative 
sestamibi scanning for primary hyperparathyroidism. Am Surg. mai 2003;69(5):393- 8; discussion 399.

4. Kannan S, Milas M, Neumann D, Parikh RT, Siperstein A, Licata A. Parathyroid nuclear scan. A focused review on the technical and biological factors affecting its outcome. Clin Cases Miner Bone Metab. 2014;11(1):25- 30.

5. Munoz-Garach A, Fernandez-Garcia D, MolinaVega M, Sebastian-Ochoa A, Del V-TMDM, Amrani-Raissouni T, et al. Biochemical response and imaging changes in 99mtc-mibi in patiens with primary hyperparathyroidism treated with Cinacalcet. In BioScientifica; 2014 [cité 6 août 2019]. Disponible sur: https://www.endocrineabstracts.org/ea/0035/ea0035p106

6. Hindié E, Ugur Ö, Fuster D, ODoherty M, Grassetto G, Ureña P, Kettle A, Gulec SA, Pons F, Rubello D. 2009 EANM parathyroid guidelines. European journal of nuclear medicine and molecular imaging. 2009 Jul;36(7):1201-16. 